\title{
Endoscopic closure of a radiation induced colovesical fistula using the novel over-the-scope Padlock Clip system-a case report
}

\author{
Keng Hoong Chiam^, Raman Muthukaruppan^ \\ Gastroenterology Unit, Queen Elizabeth Hospital, Kota Kinabalu Sabah, Malaysia \\ Correspondence to: Keng Hoong Chiam. Karung Berkunci 2029, 88586 Kota Kinabalu, Sabah, Malaysia. Email: symeon_chiam@yahoo.co.uk.
}

\begin{abstract}
Colovesical fistula (CVF) complicates a variety of condition including diverticulitis, cancer, Crohn's disease, and rarely, a late sequela from radiation therapy to pelvic malignancies. The recommended treatment to address these fistulas had always been through surgery or conservative approach. Lately, the role of endoscopic closure to fistulas with over-the-scope clips (OTSCs) has been proposed as an option to manage surgically unfit patients who are not suitable for conservative treatment. We wish to present a patient with radiation induced CVF who underwent successful endoscopic closure with the Padlock Clip Defect Closure System (STERIS). A 68-year-old lady presented with symptoms of fever, abdominal pain, and hematuria for one-week duration in addition to complains of fecaluria and pneumaturia. There was background history of cervical malignancy 12 years ago for which she successfully underwent a combination of chemoradiation and brachytherapy treatment. Clinical examination was unremarkable, but relevant biochemical investigations were consistent with urosepsis. A CT abdomen and pelvis looking for suspected enterovesical fistulas were inconclusive. Subsequently, colonoscopy with methylene blue instillation via the bladder irrigation catheter confirmed the CVF location within the rectosigmoid colon. As she was unfit for any operative procedure at that juncture, endoscopic closure of the CVF with the Padlock Clip was performed. The success of this procedure was confirmed with the absence of methylene blue flush postprocedurally. Our patient remained asymptomatic and a repeat colonoscopy 8 weeks later showed that the Padlock Clip was still in situ. Delayed complications as a result of pelvic malignancy irradiation in the form of CVF are extremely rare. Our case demonstrates a novel endoscopic closure technique that may complement the established role of surgery. We believe our case of CVF endoscopic closure with the Padlock Clip is one of the few reported cases and wish to describe its utility here.
\end{abstract}

Keywords: Colovesical fistula (CVF); Padlock Clip; over-the-scope clips (OTSCs); pelvic malignancies; case report

Received: 03 March 2021; Accepted: 16 March 2021; Published: 30 June 2021.

doi: 10.21037/asj-21-6

View this article at: http://dx.doi.org/10.21037/asj-21-6

\section{Introduction}

Colovesical fistulas (CVFs) are known complications of complicated diverticular disease, malignancy, and Crohn's colitis (1). With the increasing use of radiation therapy in relation to pelvic malignancies, we now have a rising incidence of benign radiation induced CVF that could potentially lead to recurrent bouts of cystitis, pyelonephritis, renal abscesses, renal impairment and systemic infection resulting from ongoing fecal contamination through the abnormal connection (2). The complications of urosepsis, in particular, carry high morbidity and mortality, and thus CVF should generally be an indication for surgical repair to avoid these problems (3). Unfortunately, not all patients are fit

^ ORCID: Keng Hoong Chiam, 0000-0002-8150-6286; Raman Muthukaruppan, 0000-0003-1506-6021. 


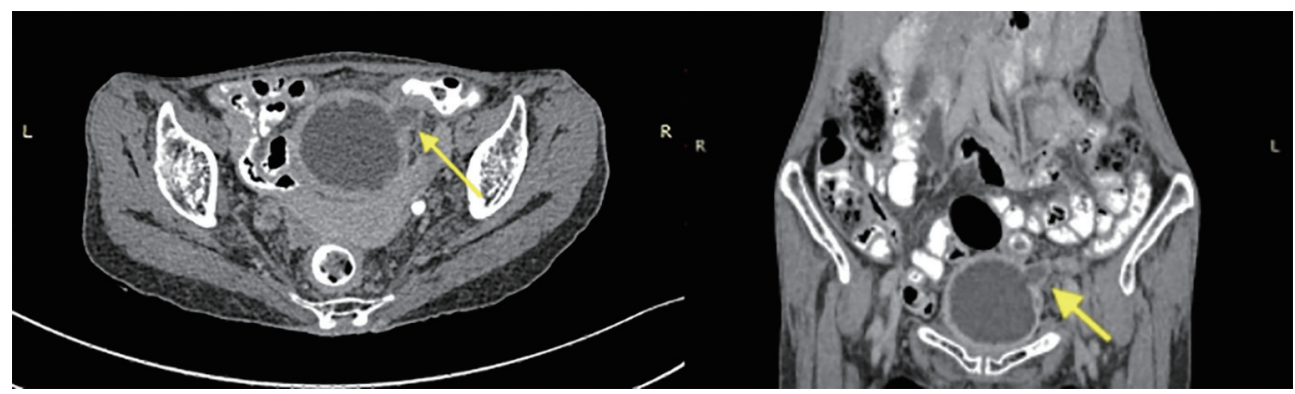

Figure 1 Axial and coronal planes of CT abdomen and pelvis showing the large diverticulum (yellow arrows).

enough for operative management. As a consequence, they are managed conservatively despite the fact that spontaneous closure only occurs about $2 \%$ of the time $(4,5)$.

Recently, with the advancement of endoscopic techniques, we are now able to venture into the prospect of endoscopic closure for intestinal fistulas. This would undoubtedly address patients who are unfit for operative intervention and might emerge as a complementary treatment option in the future.

We present a case of a patient who was successfully managed with endoscopic closure using the Padlock Clip Defect Closure System (STERIS). We present the following article in accordance with the CARE reporting checklist (available at https://asj.amegroups.com/article/ view/10.21037/asj-21-6/rc).

\section{Case presentation}

Our patient was a 68-year-old lady who presented with one week history of high-grade fever, lower abdominal pain and hematuria in addition to pneumaturia and fecaluria. Her background comorbidities included hypertension, Type II diabetes mellitus, hyperlipidemia and decompensated heart failure. In addition to this, there was also a history of cervical cancer diagnosed 12 years ago for which she successfully underwent a combination of chemoradiation and brachytherapy treatment.

Clinical examination revealed a frail and cachectic lady with a blood pressure of $80 / 40 \mathrm{mmHg}$, pulse rate of 114 beats per minute, temperature of $39^{\circ} \mathrm{C}$ and respiratory rate of 36 breaths per minute. Her oxygen saturation was $92 \%$ on room air and she was clinically pale and tachypneic. There was mild tenderness over at the suprapubic region. Other systems examination was unremarkable.

Relevant biochemical investigations revealed elevated total white cell count at $14.80 \times 10^{3} / \mu \mathrm{L}$ [normal range
(4.00-10.00) $\times 10^{3} / \mathrm{uL}$ ], hemoglobin $6.6 \mathrm{~g} / \mathrm{dL}$ (normal range $12.0-15.0 \mathrm{~g} / \mathrm{dL}$ ), C-reactive protein $31.2 \mathrm{mg} / \mathrm{L}$ (normal $<5.0 \mathrm{mg} / \mathrm{L}$ ), ferritin $511.5 \mathrm{ng} / \mathrm{mL}$ (normal range $4.6-$ $204.0 \mathrm{ng} / \mathrm{mL}$ ), serum albumin $17 \mathrm{~g} / \mathrm{L}$ (normal range 34$48 \mathrm{~g} / \mathrm{L}$ ), urea $27.3 \mathrm{mmol} / \mathrm{L}$ (normal range $3.5-7.0 \mathrm{mmol} / \mathrm{L}$ ) and creatinine $108.6 \mu \mathrm{mol} / \mathrm{L}$ (normal range 50.4 $98.1 \mu \mathrm{mol} / \mathrm{L}$ ). In addition, her urine cultures revealed mixed isolates of Enterobacter spp and Klebsiella spp. while her blood cultures yielded no growth. Our provisional diagnosis was acute kidney injury secondary to urosepsis complicated by a possible enterovesical fistula.

Our patient subsequently underwent fluid resuscitation and was started on parenteral broad-spectrum antibiotics. She then went on to have a CT abdomen and pelvis performed and this revealed a large diverticulum seen within the left dome of the urinary bladder (Figure 1). In addition, the bladder wall was also thickened in keeping with ongoing inflammation. The suspected fistula however could not be delineated. Following this, a cystoscopy performed revealed large amount of blood clots adhered to the site of the bladder diverticulum. This was not amenable for removal and attempts to locate the fistula from the bladder was unsuccessful. Subsequently, colonoscopy performed two days later revealed a $6 \mathrm{~mm}$ slit-like opening located $19 \mathrm{~cm}$ from the anal verge within the rectosigmoid colon. To confirm that this was the colonic end of the fistula, methylene blue dye was flushed through the bladder irrigation catheter and a gush of blue dye could be clearly seen flowing into the colonic lumen (Figure 2).

As she was surgically unfit to undergo a timely operative intervention which was important to treat and avoid a recurring episode of urosepsis, a collective decision with the surgeon was made to attempt endoscopic closure with an over-the-scope clip (OTSC) on the colonic end of the fistula. The Padlock Clip with a tissue chamber depth of $1.0 \mathrm{~cm}$ was selected for this purpose. The area around the 


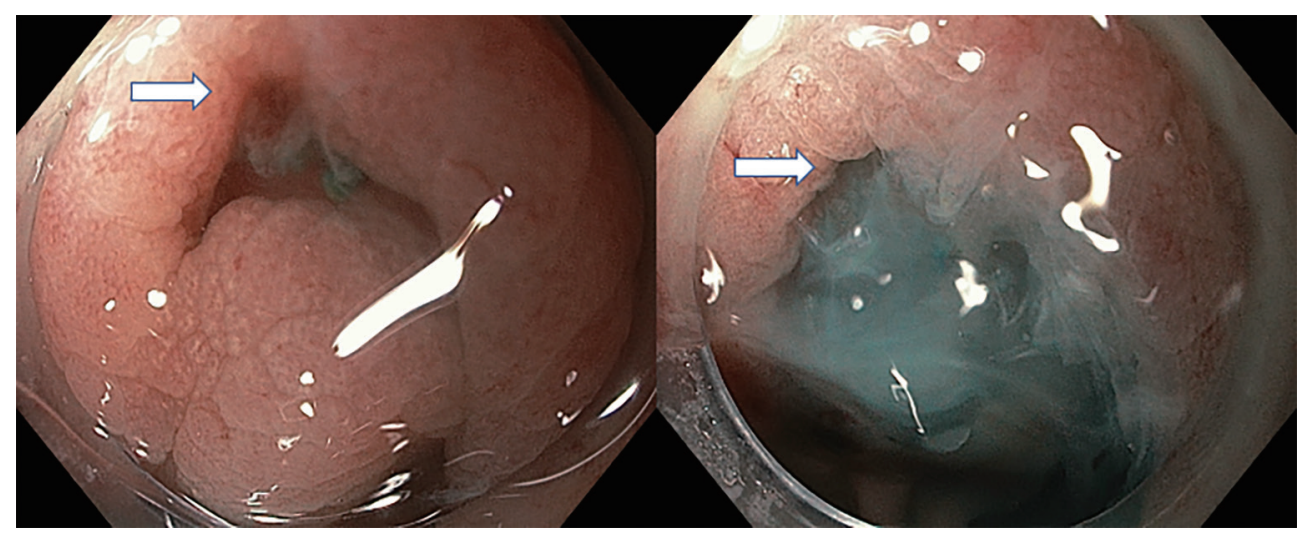

Figure 2 Colonoscopy with pre- and post-methylene blue instillation highlighting the site of the colovesical fistula. Notice the gush of blue dye flowing into the colon (white arrows).

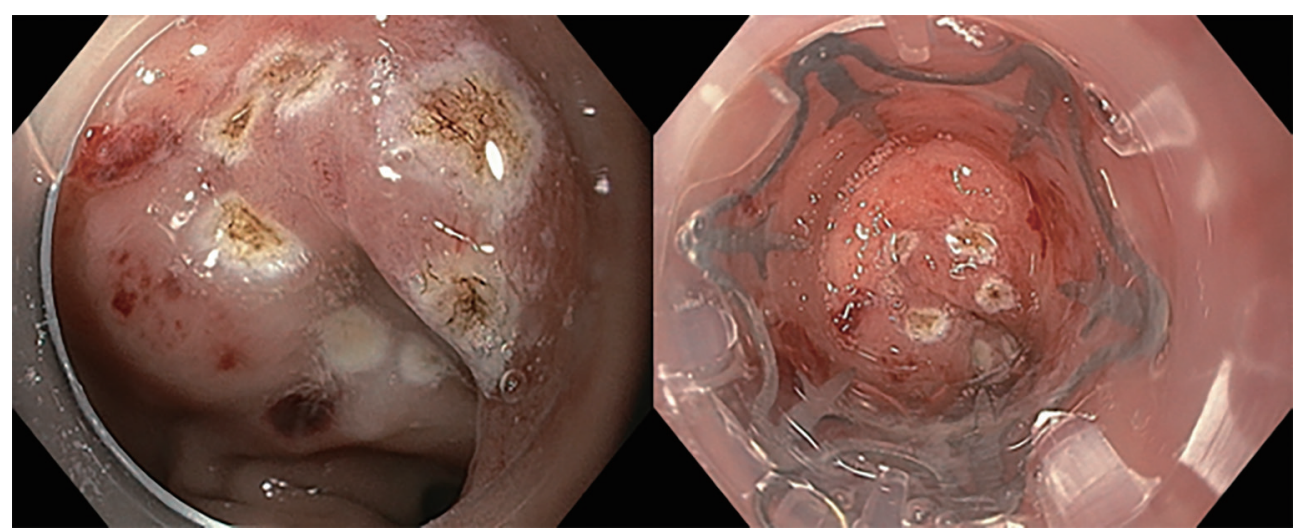

Figure 3 The colonic end of the fistula was marked with argon plasma coagulation (left) followed by OTSC deployment (right). OTSC, over-the-scope clip.

fistula was first marked with argon plasma coagulation to allow easier re-identification. Upon installation of the Padlock Clip, we re-negotiated the colonoscope back to the CVF site. Endoscopic suctioning of the marked location was then applied followed by OTSC deployment (Figure 3). The procedure was uncomplicated and deemed a success with the absence of methylene blue flush post-procedurally. A pseudopolyp marked the site of clip deployment and minor expectant bleeding tackled with snare-tip-softcoagulation technique.

Our patient was discharged well after a week's observation with immediate resolution of pneumaturia and fecaluria. A repeated colonoscopy eight weeks later revealed that the Padlock Clip was still intact (Figure 4). Her condition improved remarkably though she was not keen for further definitive intervention despite extensive counselling.

All procedures performed in this study were in accordance with the ethical standards of the institutional and/or national research committee(s) and with the Helsinki Declaration (as revised in 2013). Written informed consent was obtained from the patient for publication of this case report and accompanying images. A copy of the written consent is available for review by the editorial office of this journal.

\section{Discussion}

Colovesical fistula is the most commonly encountered entity of enterovesical fistulas constituting up to approximately $70 \%$ of the overall cases (1). The etiology of CVF encompasses a heterogenous group of both benign 


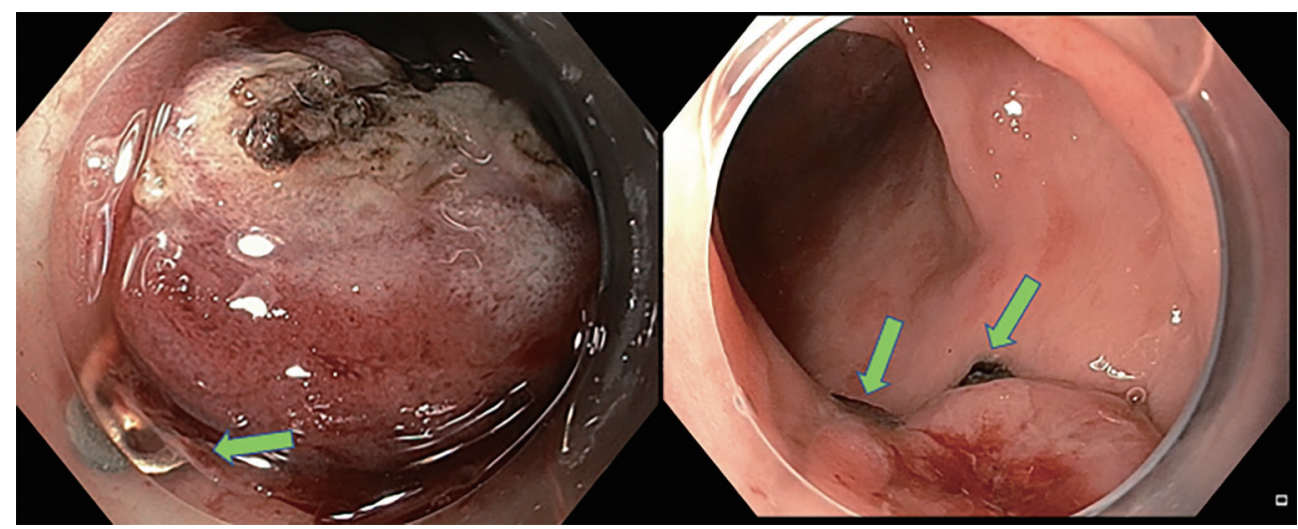

Figure 4 The pseudopolyp appearance following OTSC deployment during the index colonoscopy (left) and eight weeks later (right). The OTSC prongs could be seen (green arrows). OTSC, over-the-scope clip.

and malignant conditions. Specifically, and in relevance to our patient, its association with chronic radiation enteritis is a well-described complication despite a low reported incidence ranging from $0.3-3.0 \%$. Recognition of radiation enteritis as a potential side effect of radiotherapy is pertinent as this would help in making an early diagnosis through clinical presentation and subsequently assist in organizing relevant radiological and endoscopic evaluation. These group of patients should then be closely monitored and followed up for signs of radiation enteritis sequelae, namely fistula formation, strictures, perforation and abscesses (6-8).

Though the incidence of radiation induced CVF is relatively scarce, recent evidence indicates that with improved detection of pelvic cancers and increasing use of external beam radiotherapy and brachytherapy, a foreseeable increase in complex cases in the near future is expected to occur. In overcoming these complications, various strategies were employed with the primary aim of mitigating radiation enteritis with the most important being the reduction of radiation dose and field size of exposure. With reference to the specific treatment for radiation enteritis, guidelines were equally ambiguous with only endoscopic thermal coagulation and hyperbaric oxygen therapy showing some potential promises in palliating symptoms (8).

In terms of the definitive management for CVF, surgical resection of the involved bowel segment and associated fistula with subsequent re-anastomosis is the present standard of care to achieve the best outcome. This reduces the risk of recurrence and is better than relying on the low likelihood of spontaneous closure resulting from defunctioning colostomy. Depending on the patient's age and timing of presentation, underlying co-morbidities and concurrent medical issues, surgical options may include either a one-stage repair or multiple stages of repair (1). It must however be borne in mind that these are major procedures and there are a select few who are too ill and not sufficiently fit to undergo timely surgery. Furthermore, repeated bowel resections may become justified in the future, and the inherent risk of short-bowel syndrome needs to be considered. On the flipside, subjecting them to conservative management would not be ideal either (1).

Endoscopic through-the-scope clips (TTSCs) have been used as a combined approach in CVF closure. However, the setback was that TTSC generally falls off within an average of 10 to 14 days and might not be long enough to permit fistula healing (9). Modern advancement in endoscopic accessories has led to the development of OTSC with the initial intent of securing difficult gastrointestinal bleeding. These are large clips designed to provide superior full thickness closure strength mimicking hand suture as demonstrated in ex vivo porcine model (10). In view of this, their role in endotherapeutics has since expanded to include sealing gastrointestinal perforations, resection of early colorectal cancers and closure of iatrogenic and pathological fistulas and leaks (11-13). Early reports were both encouraging and optimistic though there were limited cases with inadequate follow-up duration. To date, there were no technical failures and intraprocedural complications for all indications though the final success rates were ultimately dependent on the size and chronicity of the primary pathology (13-15).

Historically, the first OTSC system introduced was the Ovesco Clips (Ovesco Endoscopy AG, Tübingen, Germany) followed by the more recently developed Padlock Clip 
which offered a more affordable alternative and possibly equal success in managing gastrointestinal fistulas which had no prior intervention (16-18). Additionally, there were two reported cases of failed rectovesical and rectocutaneous fistula closure with the Ovesco clips that were subsequently managed with the Padlock Clips. The patients went on to have clinical resolution for up to 8 months despite clip detachment within 30 days suggesting that it may be a reliable option in salvage therapy as well (18).

The attractive feature of the Padlock Clip is its ease of installation and the unique circumferential 6-inner prongs which offer a strong grip and watertight closure through simple tissue suctioning and thumb press clip deployment technique (19). Despite the firm grasp and compression offered by OTSCs, their unique design does not lead to tissue ischemia or laceration which is favorable in encouraging fistula healing. Unlike Ovesco Clips, the Padlock system is less studied due to its novelty, and our case serves to illustrate its versatile role in gastrointestinal fistula closure (19). Furthermore, our Padlock clip remains attached even after 8 weeks of deployment.

An important point to note in terms of technical aspect is the selection of the ideal gastrointestinal fistulas for endoscopic closure. In general, the fistula should allow an unobtrusive view where it is easily accessible and intervention is feasible. Bearing in mind that the colonoscope fitted with a long distal attachment device would be difficult to negotiate colonic loops, the location of the fistula also plays a significant factor in determining technical success. In this regard, the ability to obtain a shortened and straight endoscope is vital to ensure the ease of maneuverability during OTSC application. The surrounding colonic mucosa should also be healthy and not friable or necrotic to encourage optimal OTSC deployment (20).

The OTSC is indeed an innovative device though more research is warranted to address its long-term efficacy, technical failures, limitations of use in terms of fistula size and complications before wider implementation. As of the present status, OTSC and in particular the Padlock Clip (as shown in our patient) can be offered as a temporizing measure following multidisciplinary discussions on a case-bycase basis until more definitive treatment could be offered.

\section{Conclusions}

The introduction of OTSCs in performing CVF closure offers a novel endoscopic approach in bridging the management gap for patients who could not undergo timely surgery while at the same time are not suitably managed conservatively. The simple installation of the Padlock Clip prior to its application, ease of use and rapid deployment are attractive features in performing endoscopic gastrointestinal fistula closure. Looking forward, endoscopic intervention for fistula closure using Padlock Clips may have a more definitive role for these heterogenous groups of pathology though larger scale studies with longer follow-ups are eagerly awaited.

\section{Acknowledgments}

We would like to acknowledge our team of gastroenterology fellows who assisted in the patient's management. They are Dr. Chee Men Lu and Dr. Cha Chee Tan. Funding: None.

\section{Footnote}

Reporting Checklist: The authors have completed the CARE reporting checklist. Available at https://asj.amegroups.com/ article/view/10.21037/asj-21-6/rc

Conflicts of Interest: Both authors have completed the ICMJE uniform disclosure form (available at https://asj.amegroups. com/article/view/10.21037/asj-21-6/coif). The authors have no conflicts of interest to declare.

Ethical Statement: The authors are accountable for all aspects of the work in ensuring that questions related to the accuracy or integrity of any part of the work are appropriately investigated and resolved. All procedures performed in this study were in accordance with the ethical standards of the institutional and/or national research committee(s) and with the Helsinki Declaration (as revised in 2013). Written informed consent was obtained from the patient for publication of this case report and accompanying images. A copy of the written consent is available for review by the editorial office of this journal.

Open Access Statement: This is an Open Access article distributed in accordance with the Creative Commons Attribution-NonCommercial-NoDerivs 4.0 International License (CC BY-NC-ND 4.0), which permits the noncommercial replication and distribution of the article with the strict proviso that no changes or edits are made and the original work is properly cited (including links to both the formal publication through the relevant DOI and the license). 
See: https://creativecommons.org/licenses/by-nc-nd/4.0/.

\section{References}

1. Keady C, Hechtl D, Joyce M. When the bowel meets the bladder: Optimal management of colorectal pathology with urological involvement. World J Gastrointest Surg 2020;12:208-25.

2. Levenback C, Gershenson DM, McGehee R, et al. Enterovesical fistula following radiotherapy for gynecologic cancer. Gynecol Oncol 1994;52:296-300.

3. Rodkey GV, Welch CE. Changing patterns in the surgical treatment of diverticular disease. Ann Surg 1984;200:466-78.

4. Solkar MH, Forshaw MJ, Sankararajah D, et al. Colovesical fistula--is a surgical approach always justified? Colorectal Dis 2005;7:467-71.

5. Karamchandani MC, West CF. Vesicoenteric fistulas. Am J Surg 1984;147:681-3.

6. Tran H, Flannigan R, Rapoport D. Transperineal approach to complex rectourinary fistulae. Can Urol Assoc J 2015;9:E916-20.

7. Iwamuro M, Hasegawa K, Hanayama $\mathrm{Y}$, et al. Enterovaginal and colovesical fistulas as late complications of pelvic radiotherapy. J Gen Fam Med 2018;19:166-9.

8. Ali S, Habib I. Pharmacological interventions for the prevention and treatment of radiation colitis, enteritis and proctitis. Cochrane Database of Systematic Reviews 2011(2). Available online: https://www.cochranelibrary. com/cdsr/doi/10.1002/14651858.CD008971/full

9. Shin EJ, Ko CW, Magno P, et al. Comparative study of endoscopic clips: duration of attachment at the site of clip application. Gastrointest Endosc 2007;66:757-61.

10. Voermans RP, Vergouwe F, Breedveld P, et al. Comparison of endoscopic closure modalities for standardized colonic perforations in a porcine colon model. Endoscopy 2011;43:217-22.

doi: 10.21037/asj-21-6

Cite this article as: Chiam KH, Muthukaruppan R. Endoscopic closure of a radiation induced colovesical fistula using the novel over-the-scope Padlock Clip system-a case report. AME Surg J 2021;1:5.
11. Schmidt A, Beyna T, Schumacher B, et al. Colonoscopic full-thickness resection using an over-the-scope device: a prospective multicentre study in various indications. Gut 2018;67:1280-9.

12. Aepli P, Criblez D, Baumeler S, et al. Endoscopic full thickness resection (EFTR) of colorectal neoplasms with the Full Thickness Resection Device (FTRD): Clinical experience from two tertiary referral centers in Switzerland. United European Gastroenterol J 2018;6:463-70.

13. Raju GS. Endoscopic clip closure of gastrointestinal perforations, fistulae, and leaks. Dig Endosc 2014;26 Suppl 1:95-104.

14. Manta R, Manno M, Bertani H, et al. Endoscopic treatment of gastrointestinal fistulas using an over-thescope clip (OTSC) device: case series from a tertiary referral center. Endoscopy 2011;43:545-8.

15. Lee HL, Cho JY, Cho JH, et al. Efficacy of the Overthe-Scope Clip System for Treatment of Gastrointestinal Fistulas, Leaks, and Perforations: A Korean Multi-Center Study. Clin Endosc 2018;51:61-5.

16. Armellini E, Crinò SF, Orsello $M$, et al. Novel endoscopic over-the-scope clip system. World J Gastroenterol 2015;21:13587-92.

17. Brindley JH, Yip B, Vlachou E, et al. Successful endoscopic closure of a gastrocutaneous fistula using a 'Padlock Clip'. Endoscopy 2016;48 Suppl 1:E115-6.

18. Dinelli M, Omazzi B, Andreozzi P, et al. First clinical experiences with a novel endoscopic over-the-scope clip system. Endosc Int Open 2017;5:E151-E156.

19. Desilets DJ, Romanelli JR, Earle DB, et al. Gastrotomy closure with the lock-it system and the Padlock-G clip: a survival study in a porcine model. J Laparoendosc Adv Surg Tech A 2010;20:671-6.

20. Bhurwal A, Mutneja H, Tawadross A, et al. Gastrointestinal fistula endoscopic closure techniques. Ann Gastroenterol 2020;33:554-62. 